\title{
British Journal of General Practice
}

\section{Identifying individuals with persistently normal safety monitoring blood tests whilst taking methotrexate for rheumatoid arthritis or azathioprine for inflammatory bowel disease: a retrospective cohort study.}

Fraser, Simon; Lin, Sharon; Stammers, Mathew; Culliford, David; Ibrahim, Kinda; Barrett, Ravina; Howard, Clare; Johnson, Ruth; Barnes, Nicola; Batchelor, James; Holroyd, Christopher; Adams, Jo; Rischin, Adam; Roderick, Paul; Rutter, Paul; Edwards, Christopher

DOI: https://doi.org/10.3399/BJGP.2021.0595

To access the most recent version of this article, please click the DOI URL in the line above.

Received 18 October 2021

Revised 17 December 2021

Accepted 07 January 2022

(C) 2022 The Author(s). This is an Open Access article distributed under the terms of the Creative Commons Attribution 4.0 License (http://creativecommons.org/licenses/by/4.0/). Published by British Journal of General Practice. For editorial process and policies, see:

https://bjgp.org/authors/bjgp-editorial-process-and-policies

When citing this article please include the DOI provided above.

\section{Author Accepted Manuscript}

This is an 'author accepted manuscript': a manuscript that has been accepted for publication in British Journal of General Practice, but which has not yet undergone subediting, typesetting, or correction. Errors discovered and corrected during this process may materially alter the content of this manuscript, and the latest published version (the Version of Record) should be used in preference to any preceding versions 


\section{$\underline{\text { Title }}$}

Identifying individuals with persistently normal safety monitoring blood tests whilst taking methotrexate for rheumatoid arthritis or azathioprine for inflammatory bowel disease: a retrospective cohort study.

Dr Simon DS Fraser ${ }^{1,2}$ BM, DM, MRCGP, FFPH, Associate Professor of Public Health

Dr Sharon X Lin ${ }^{1,2}, P h D$, Research Fellow

Dr Matthew Stammers ${ }^{3,4}, M B B S, M R C P$ (Gastroenterology) Consultant Gastroenterologist \& Digital Fellow

Dr David Culliford $2,10, P h D$, Principal Medical Statistician

Dr Kinda Ibrahim $2,5, P h D$, Senior Research Fellow

Mrs Ravina Barrett ${ }^{6}$, MPharm, FHEA, MSc Finance, Senior Lecturer in Pharmacy Practice

Ms Clare Howard7 , FFRPS FRPharmS Clinical Lead Medicines Optimisation

Ms Ruth Johnson ${ }^{8}$, BSc, FEDIP-SenPra, BI Consultant

Dr Nicola Barnes ${ }^{9}, P h D$, PGCert, MPharm(Hons), Senior Lecturer of Pharmacy Practice

Prof James Batchelor ${ }^{4}$, Professorial Fellow of Clinical Informatics and Healthcare Innovation and

Director of the Clinical Informatics Research Unit

Dr Christopher Holroyd ${ }^{3}, F R C P, P h D$, Consultant Rheumatologist

Prof Jo Adams ${ }^{10}$, PhD Emeritus Professor of Musculoskeletal Health

Dr Adam Rischin ${ }^{11}$, MBBS (Hons), FRACP, Rheumatologist

Prof Paul Roderick ${ }^{1}, M D, F F P H$, Professor of Public Health

Prof Paul Rutter ${ }^{9}, P h D$, Professor of Pharmacy Practice

Prof Christopher J Edwards ${ }^{12}$, BSc, MBBS, MD, FRCP Professor of Rheumatology and Associate

Director of NIHR Clinical Research Faculty, University of Southampton

1. School of Primary Care, Population Sciences and Medical Education, Faculty of Medicine, University of Southampton, Southampton General Hospital, Southampton, SO16 6YD, UK.

2. NIHR ARC Wessex, Southampton Science Park, Innovation Centre, 2 Venture Road, Chilworth, Southampton, SO16 7NP

3. University Hospital Southampton NHS Foundation Trust, Southampton General Hospital, Southampton, SO16 6YD, UK.

4. Clinical Informatics Research Unit, University of Southampton, UK

5. Academic Geriatric Medicine, Faculty of Medicine, University of Southampton UK 
6. School of Pharmacy and Biomolecular Sciences, Cockcroft Building, University of Brighton, Moulsecoomb, Brighton, BN2 4GJ

7. Wessex AHSN, Southampton Science Park, Innovation Centre, 2 Venture Rd, Chilworth, Southampton SO16 7NP, UK.

8. Commissioning Support Unit, NHS South, Central and West, Omega House, 112 Southampton Road, Eastleigh, Hampshire, SO50 5PB, UK.

9. School of Pharmacy and Biomedical Sciences, University of Portsmouth, White Swan Road, Portsmouth PO1 2DT, UK.

10. School of Health Sciences, University of Southampton, University Road, Southampton, SO17 1BJ, UK.

11. Alfred Health, Melbourne, Australia

12. NIHR Southampton Clinical Research Facility, University Hospital Southampton NHS Foundation Trust, Southampton.

Corresponding author: Simon DS Fraser ${ }^{1,2}$ 


\section{Abstract}

\section{Background}

Disease-modifying anti-rheumatic drugs (DMARDs), including methotrexate and azathioprine, are commonly used for rheumatoid arthritis (RA) and inflammatory bowel disease (IBD). Blood test safety monitoring is mainly undertaken in primary care. Normal blood results are common.

\section{Aim}

To determine the frequency and associations of persistently normal blood tests in RA patients prescribed methotrexate and IBD patients prescribed azathioprine.

\section{Design and setting}

Two-year retrospective cohort study using pseudonymised primary care/laboratory data in Hampshire.

\section{Method}

RA and IBD patients were identified with associated methotrexate (RA) and azathioprine (IBD) prescriptions. NICE-recommended tests and thresholds were applied and persistent normality defined as a) no abnormalities of any tests, and b) individually for alanine aminotransferase (ALT), estimated glomerular filtration rate (eGFR), white blood count (WBC), and neutrophils. Logistic regression was used to identify associations with test normality.

\section{Results}

Of 702,265 adults, 7102 had RA and 8597 had IBD. 3001 (42.2\%) RA patients were prescribed methotrexate and $1162(13.5 \%)$ IBD patients prescribed azathioprine. Persistently normal tests occurred in 1585 (52.8\%) of the RA/methotrexate and 657 (56.5\%) of the IBD/azathioprine populations. In RA/methotrexate patients 585 (19.5\%) had eGFR, 219 (7.3\%) ALT, 217 (7.2\%) WBC, and 202 $(6.7 \%)$ neutrophil abnormalities. In IBD/azathioprine patients 138 (4.6\%) had WBC, 88 (2.9\%) eGFR, $72(2.4 \%)$ ALT and 65 (2.2\%) neutrophil abnormalities. Those least likely to have persistent test normality were older and/or had comorbidities.

\section{Conclusions}

Persistent test normality is common in monitoring these DMARDs in primary care, with few hepatic or haematological abnormalities. More stratified monitoring approaches should be explored. 


\section{How this fits in}

Conventional synthetic disease-modifying anti-rheumatic drugs (DMARDs) such as methotrexate and azathioprine are commonly used to treat rheumatoid arthritis (RA) and inflammatory bowel disease (IBD) in the UK. Their ongoing prescribing and blood test safety monitoring are mainly undertaken in primary care. The National Institute of Health and Care Excellence (NICE) guides the tests used, thresholds for abnormality and testing frequency. Once established on methotrexate or azathioprine, three monthly blood tests are recommended, which represents a workload for patients and health services. Abnormalities of these monitoring blood test results are relatively uncommon and, in most cases, unlikely to reflect serious DMARD-related toxicity, raising questions about recommended testing frequency and thresholds.

We used two years' data from a large primary care database in Hampshire, UK to explore the frequency and associations of persistently normal NICE-recommended blood tests in RA patients taking methotrexate and IBD patients taking azathioprine. We found that persistent blood test normality was common and abnormalities were dominated by reduced renal function among older people, with relatively few hepatic or haematological abnormalities. Greater stratification of monitoring approaches may reduce workload and costs for patients and health services, but evidence is required on long-term safety, acceptability and cost-effectiveness of changing current practice. 


\section{Introduction}

Rheumatoid arthritis (RA) and inflammatory bowel disease (IBD) are common inflammatory conditions with prevalence of $0.8 \%(0.4 \%$ in men, $1.2 \%$ in women) and $0.7 \%$ (ulcerative colitis about $0.4 \%$, Crohn's disease $0.3 \%$ ) respectively. ${ }^{1,2}$ Disease-modifying anti-rheumatic drugs (DMARDs), including synthetic and biological agents, are used to control disease activity and progression. ${ }^{3-6}$ The commonest synthetic DMARDs in the UK are methotrexate for RA and azathioprine for IBD. ${ }^{3-5}$ Both require regular safety blood test monitoring for liver function abnormalities, kidney function and bone marrow toxicity, frequently at initiation and then less frequently once a maintenance dose is established. ${ }^{7}$ In the UK methotrexate or azathioprine initiation usually occurs in secondary care with blood test monitoring and on-going repeat prescribing undertaken in primary care as recommended by the National Institute for Health and Care Excellence (NICE)., ${ }^{7,8}$ Guidelines include recommendations to 'consider stopping treatment and referring urgently' if results show abnormalities..$^{7,9}$ Regular blood test monitoring has been linked with anxiety and depression for some patients and incurs substantial costs for healthcare providers, and workload for clinicians, laboratory staff and administrators. ${ }^{10-13}$ Despite guidelines, the optimal monitoring frequency has not been established. ${ }^{3-6}$ The extent to which patients taking DMARDs experience prolonged periods with no abnormal tests is unclear. A review of RA monitoring schedules concluded that drug-related toxicities are infrequent and that clear evidence for monitoring preventing harm is lacking. ${ }^{14}$ Targeted monitoring of higher-risk individuals and reduced monitoring for lower-risk patients may improve health service efficiency and reduce patient workload, provided safety is established.

This study aimed to assess the extent of, and factors associated with, persistently normal NICErecommended blood tests among people with RA taking methotrexate and IBD taking azathioprine to inform monitoring strategies. We also describe frequency of blood testing as an indication of health service and patient workload.

\section{Method}


The study cohort was taken from the Care and Health Information Analytics database (CHIA), a pseudonymised electronic database containing primary care data for over 1.4 million patients registered with General Practice (GP) surgeries across Hampshire and the Isle of Wight, UK with linked clinical biochemistry and haematology data from two large NHS hospital laboratories (Southampton and Portsmouth). The study population consisted of adults (aged 18+) registered with GP practices that consistently sent all laboratory data to either hospital for the entire study duration and who were alive on 1st October 2017 and survived until 30 September 2019. It was therefore a retrospective 'closed' cohort in whom clinical diagnoses and complete biochemical and haematological data were available (both GP-ordered tests and all hospital-ordered tests). ${ }^{15}$ 'Baseline' was defined as the first two-month study period (October 2017-November 2017) to describe prescribing patterns.

People with RA and IBD were identified using Read codes (codes used to record long-term conditions and other aspects of medical encounters in Primary Care systems in England) and described as prevalent (those with a diagnosis of RA or IBD in their medical record at baseline) and incident (those with first RA or IBD coding occurred during follow up (October 2017 to September 2019). ${ }^{16}$ DMARD prescription was defined as having at least one primary care-issued prescription of methotrexate or azathioprine in any two-month period across the two years. Two-month periods were chosen because repeat prescribing in the UK commonly adopts a one or two-month prescription pattern. Finer data cuts might mislabel some as being prescribed or not prescribed at any given time. Age was defined in years based on birthdate prior to pseudonymisation (date of birth was not available to the study team). Ethnicity was categorised into white, Indian/Bangladeshi/Pakistani, African/Caribbean, Mixed and other). Socioeconomic status was defined using 2015 Index of Multiple Deprivation (IMD) quintiles. ${ }^{17}$ IMD is a small-area measure of socioeconomic status based on postcode, ranked nationally, comprising seven domains: income, employment, education/skills/training, health and disability, crime, barriers to housing and services, living environment. Comorbidities were defined using Read codes as described previously (NB not all conditions were available in our dataset). ${ }^{18}$ Blood test data included liver function, renal function and full blood count. 


\section{Outcomes}

Our main outcomes were lack of blood test abnormality while being prescribed methotrexate for RA or azathioprine for IBD.

Firstly, we identified people in both disease/DMARD groups (RA/methotrexate and IBD/azathioprine) meeting all of these NICE-specified normality thresholds (Supplementary Box 1) 7,8 .

- White blood count (WBC) $3.5 \times 10^{9} / \mathrm{L}$ or above

- Mean cell volume $105 \mathrm{fL}$ or less

- Neutrophils $1.6 \times 10^{9} / \mathrm{L}$ or above

- Platelets $140 \times 10^{9} / \mathrm{L}$ or above

- Eosinophils $0.5 \times 10^{9} / \mathrm{L}$ or less

- Alanine aminotransferase (ALT) $100 \mathrm{U} / \mathrm{L}$ or less

- Aspartate transaminase (AST) $100 \mathrm{U} / \mathrm{L}$ or less

- Albumin $30 \mathrm{~g} / \mathrm{L}$ or more

- Estimated glomerular filtration rate (eGFR) $60 \mathrm{ml} / \mathrm{min} / 1.73 \mathrm{~m}^{2}$ or more. ${ }^{7}$

Secondly, we considered ALT, eGFR, WBC and neutrophils individually (at these NICE-recommended thresholds).

\section{Statistical analyses}

Descriptive statistics were used to identify prevalence and patterns of methotrexate and azathioprine exposure in each two-month period among people with RA and IBD at baseline and incident RA and IBD across the study period.

Total numbers of ALT, eGFR and WBC tests were identified for the complete RA and IBD populations, those with RA taking methotrexate and IBD taking azathioprine, and for those with RA and IBD taking methotrexate and azathioprine continually over two years. To explore under-monitoring, the proportions of those with RA and IBD taking methotrexate and azathioprine continually over two years with tests in all eight three-month testing periods, in seven periods, six, five and so on was calculated for ALT, WBC 
and eGFRs. Socio-demographic characteristics of those with six or fewer ALT, eGFR and WBC tests were identified. Given the eight three month periods in the 24 months covered by this study and the potential for individuals to have had a blood test just before or just after the study period we chose six or fewer as a way of reflecting failure to adhere to the recommended three monthly pattern. Incidence of normal and abnormal blood tests was established using NICE-specified tests and thresholds as above. Numbers and characteristics of people with normality of all tests were identified and described for people with RA and IBD for any period of methotrexate and azathioprine prescription respectively. Numbers/proportions of people with persistent normality of individual tests (ALT, eGFR, WBC, neutrophils) were described.

Multivariable logistic regression was used to explore associations between patient characteristics and persistent NICE blood test normality in the RA/methotrexate and IBD/azathioprine populations. Absolute risk of blood test normality was calculated for specific age and comorbidity groups for each condition using NICE thresholds and tests, and red/amber/green risk diagrams developed using exploratory thresholds to demonstrate the potential utility of such risk stratification in clinical practice. All analyses were conducted in $\mathrm{R}$ version 3.6.3.19 The study is reported using The REporting of studies Conducted using Observational Routinely-collected health Data (RECORD) Statement (Supplementary Table 4). ${ }^{20}$ Ethical approval was obtained from University of Southampton Faculty of Medicine Research Ethics Committee (Submission ID: 53312), and UK Health Research Authority (19/HRA/6613). Data extraction from the CHIA database was approved by the Care and Health Information Exchange Information Governance Group.

\section{Results}

The cohort comprised 702,265 people registered with 85 GP practices (Figure 1). Mean age was 52, $53 \%$ were female. About $15 \%$ lived in the most deprived IMD quintile. Most were of British/Mixed British ethnicity, though ethnicity data were missing for 35\% (Table 1). At baseline, $6273(0.9 \%)$ had a history of RA and 7834 (1.1\%) IBD. During two years' follow up, 829 further people were diagnosed RA and 
763 IBD (Figure 1). At baseline, 2214 (32.9\%) people with RA were prescribed methotrexate and 746 (9.5\%) people with IBD were prescribed azathioprine. The total number of people with RA (prevalent and incident) was 7102, of whom 3001 (42.2\%) were prescribed methotrexate over two years. There were 8597 people with IBD (prevalent and incident) of whom $1162(13.5 \%)$ were prescribed azathioprine. The overall percentage prescribed fell slightly in this closed cohort with only small numbers of people with IBD prescribed methotrexate and even smaller numbers with RA prescribed azathioprine (Supplementary Figure 1 and Box 2).

There were 44,838 and 12,724 ALT tests in the full RA and IBD populations respectively, with 47,772 (RA) and 13,739 (IBD) WBC tests, and 95,162 (RA) and 26,673 (IBD) eGFRs. Both populations showed considerable variation in testing frequency, with eGFR the most frequent (Figure 2 and Supplementary Figure 2). Among the 1361 people with RA at baseline prescribed two year's methotrexate continually, the majority (over 65\%) had ALT, WBC and eGFR testing in every 3-month period (Figure 2a). By contrast, among 365 people with IBD at baseline prescribed azathioprine continually, less than $40 \%$ had testing in every three month period (Figure $2 \mathrm{~b}$ ). The sociodemographic characteristics of those having six or fewer tests were similar to those of the full RA/methotrexate and IBD/azathioprine populations. (Supplementary Table1).

\section{$R A /$ methotrexate}

Of the 3001 people with RA prescribed methotrexate, 1585 (52.8\%) had no abnormalities of any NICEspecified blood tests over two years (Table 2). Those with normal tests were generally younger and without comorbidities, particularly CKD and heart failure (Table 2, Figure 3). Among people under 60 more than $60 \%$ had no test abnormalities compared with fewer than $30 \%$ among those aged $80+$ (Table 2). Commonest abnormalities were eGFR in older people (Figure 3) and those with CKD and/or heart failure. Nearly $20 \%$ had abnormal eGFR, which showed a steep age gradient, while $219(7.3 \%)$, $217(7.2 \%)$ and 202 (6.7\%) had abnormal ALT, WBC and neutrophils respectively. For people with other comorbidities the commonest abnormality was also eGFR. 
Of the 1162 people with IBD prescribed azathioprine, 657 (56.5\%) had no abnormalities of any NICEspecified blood tests over two years. The number and proportion with test abnormalities were lower overall in the IBD/azathioprine group than in the RA/methotrexate group. Again the pattern of normality/abnormality with age varied between tests, dominated by abnormal renal function in those 80 or over (Figure 3), those with CKD and heart failure but the number of older people with specific comorbidities was small and findings should be interpreted cautiously (Table 2). WBC was the commonest individual abnormality (138 people, $4.6 \%$ ), followed by eGFR $(88,2.9 \%)$, ALT (72, $2.4 \%)$, and neutrophils $(65,2.2 \%)$.

\section{Multivariable associations}

On multivariable regression adjusting for age, sex, socioeconomic status and long-term conditions, those with RA/methotrexate least likely to have normal blood tests were older, those with CKD, cardiovascular disease or diabetes (Table 3). In the IBD/azathioprine group, those aged 40-59 were more likely to have normal blood tests (Table 3). Small numbers in the IBD/azathioprine group aged 80 and above or having CKD mean results should be treated cautiously.

Absolute risk

In the RA/methotrexate population, absolute risk of persistently normal blood tests was lowest among those aged 80 and above and those aged 60-79 with combinations of diabetes/CKD/CVD, with similar findings for the IBD/azathioprine group (Supplementary Tables 1\&2 and Supplementary Figure 2).

\section{Discussion}

\section{Summary}

In a large, two-year retrospective cohort study using linked primary care and laboratory data, this study assessed the extent of, and factors associated with, persistently normal blood tests among people with RA taking methotrexate and IBD taking azathioprine. It showed that about half of those taking methotrexate for RA or azathioprine for IBD experienced no blood test abnormality using NICErecommended tests and thresholds. For RA patients taking methotrexate, abnormalities were 
dominated by reduced renal function among older people. For IBD patients taking azathioprine, individual blood test abnormalities were less common overall and mainly constituted reduced renal function among the smaller number of older people and those with comorbidities. The absolute risk of having persistently normal blood tests was lowest among older people and those with comorbidities. A smaller proportion of people with IBD taking azathioprine continuously had regular three monthly blood tests compared with those with RA taking methotrexate continuously.

\section{Strengths and limitations}

Strengths included a large sample size with coding for long-term conditions, linkage to hospital laboratory data (enabling analysis of all blood results) and prescribing data at individual level. Limitations included potential for routine data coding errors influencing our estimated RA and IBD disease prevalence and incidence, maximum two-year follow up, preventing capture of later-occurring DMARD-induced abnormalities and, for those prescribed DMARDs at baseline, lack of information about historical prescribing. If people moved out of the area during the study period their data would stop being captured and the proportion of people with RA and IBD on DMARDs was slightly lower than other studies. This limited results for some subgroups and suggested that, for some, coding for RA or IBD may reflect a historic diagnosis, which may also have affected our baseline prevalence estimates, as shown in other studies. ${ }^{21,22}$ However, as our interest was those with both diagnosed RA or IBD and prescribed methotrexate or azathioprine, this is unlikely to have had major implications. We were unable to consider methotrexate and azathioprine dosage and some patients may not have been captured if predominantly cared for in hospital (though this is considered unlikely as information is shared frequently between primary and secondary care). We also did not have data on 6-

mercaptopurine (used to treat IBD). However, in a recent, large retrospective analysis of data from the IBD BioResource in the UK, of 11,928 participants treated with a thiopurine, the majority (94\%) received azathioprine, while about $23 \%$ received 6 -mercaptopurine, which included about $17 \%$ who received both. ${ }^{23}$ 
We had no information on dispensing or adherence (an unavoidable limitation of studying prescribing data) and lacked information on reasons for performing blood tests, so were unable to distinguish those conducted for DMARD monitoring. This means that neither higher testing frequency nor abnormalities of blood tests can be causally attributed to DMARDs in our study. We also did not explore magnitude of abnormalities in relation to upper limits of normal. IBD was not separated into Crohn's and ulcerative colitis in our data precluding exploration of differences in prescribing/testing patterns. Finally, as an observational study, there is potential for unmeasured confounding.

\section{Comparison with existing literature}

This study adds to evidence informing monitoring schedules for DMARDs by suggesting there may be lower-risk populations potentially suitable for reduced blood test monitoring frequencies, particularly younger RA patients without comorbidities. Abnormalities were dominated by reduced renal function and, while methotrexate may cause kidney injury directly in rare circumstances, the main purpose of monitoring renal function is the increased risk of methotrexate toxicity, including bone marrow suppression, in renal impairment and older age.${ }^{24}$ Cumulative incidence of myelotoxicity was only $7 \%$ among 8302 patients with IBD in a meta-analysis of 66 studies - equalling about $3 \%$ per patient and year of treatment. ${ }^{25}$ Our findings do not refute the need for renal function monitoring but the high frequency of creatinine/eGFR testing we observed, particularly in RA, suggests there may be some over-testing. CKD prevalence was $5.2 \%$ in our total baseline population, but $13.4 \%$ among RA/methotrexate patients. Monitoring for myelotoxicity therefore remains important, while remembering that renal function may be reduced but stable. This is useful for GPs considering NICE

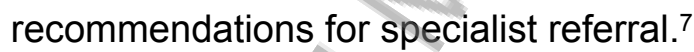

We identified low rates of liver function abnormality with $7.3 \%$ of people with RA on methotrexate and $2.4 \%$ of people with IBD on azathioprine having abnormal ALT over two years. This is in keeping with a systematic review of 47 studies of methotrexate-related liver toxicity in rheumatoid and psoriatic arthritis (mean 3.5 years methotrexate use) that found a pooled cumulative incidence of elevated liver enzymes 
of $31 \%$ but showed these abnormalities were often transient, with methotrexate being continued without adjustment in over $65 \%$ of patients in 12 of 18 studies. ${ }^{26}$ However, safety considerations may require that decisions about optimal blood testing frequency be based on risk of more serious outcomes rather than transient blood abnormalities. Incidence of severe liver abnormalities in the Visser study was low at four year's methotrexate use, with severe fibrosis in $1.3 \%$ and cirrhosis in $0.5 \% .{ }^{26}$ In a large cohort study including 28,030 individuals with RA taking methotrexate, incidence was low at 1.39 and 0.22 per 1000 person years for mild liver disease and cirrhosis respectively during mean follow up time of over eight years. ${ }^{27}$ Methotrexate-induced liver abnormalities may appearing over long time frames, raising concern about reducing testing frequency. ${ }^{26,28,29}$

We found significant variation in blood monitoring frequency, with most people having nine or more blood tests over two years, illustrating a substantial workload for patients and health services. Blood test numbers were higher in RA than IBD, particularly EGFR, perhaps reflecting older age and higher prevalence of comorbidities. A recent review of blood test monitoring identified that both under- and over-monitoring are common. ${ }^{30}$ In our study, in the RA/methotrexate and IBD/azathioprine populations prescribed these medicines continually throughout the whole two years, there were marked differences in under-testing with less than $40 \%$ of people in the continuous IBD/azathioprine group having tests in every three month period, potentially reflecting a higher proportion of the IBD group being of working age.

\section{Implications for research and practice}

Research is needed to identify whether reducing frequency of testing and/or using other tests (such as liver fibrosis markers) would affect risk of important outcomes, including liver disease. Understanding the acceptability of reducing monitoring among patients and clinicians is also important. Reducing monitoring may cause anxiety for both about the risk of serious and undetected DMARD complications. Improving understanding of risk profile variation among people on DMARDs aligns with UK National Health Service endeavours towards stratified and personalised medicine, which underline the need to 
tailor treatments to individual characteristics and adopt more targeted disease-management strategies. ${ }^{31,32}$ Work is needed to model optimal testing frequencies for people in different risk strata, to consider biological DMARDs, and to reduce unnecessary patient workload. There is potential to improve monitoring efficiency and sustainability by adjusting monitoring according to risk (if safety is considered acceptable).

As populations emerge from the Covid-19 pandemic there are likely large numbers of people taking DMARDs who have been unable to access monitoring blood tests. A recent survey among European Alliance of Associations for Rheumatology (EULAR) organisations in 35 countries, including the UK, identified that 'Cancellation or postponement of non-urgent tests either by the service provider or by patients themselves were reported by 699/1030 (68\%) and $426(41 \%)$ respondents, respectively'. ${ }^{33}$ British Society for Rheumatology Covid-19 Guidelines recommended the need for flexibility in blood testing for patients on stable DMARDs during the pandemic and a recommendation to review cases on an individual basis. ${ }^{34}$ Our findings can support prioritisation decisions when catching up with a backlog of people requiring testing.

\section{Conclusion}

Persistent normality of blood tests used to monitor methotrexate for RA and azathioprine for IBD using NICE-specified thresholds is common and abnormalities are primarily driven by older age and abnormal renal function. More stratified approaches where younger people and those without comorbidities are considered for lower blood test monitoring frequency may reduce workload and costs for patients and health care providers, particularly in primary care. More research is required to determine long-term safety, acceptability, sustainability and cost implications of changing monitoring strategies. 


\section{Funding}

This report is independent research funded/supported by the National Institute for Health Research (NIHR) Applied Research Collaboration (ARC) Wessex. The views expressed in this publication are those of the author(s) and not necessarily those of the National Institute for Health Research or the Department of Health and Social Care.

\section{Ethical approval}

Ethical approval for the study was obtained from the University of Southampton Faculty of Medicine research Ethics Committee (Submission ID:53312), and the UK Health Research Authority (19/HRA/6613).

Approval for the extraction of data from the Care and Health Information Analytics database was provided by the Care and Health Information Exchange Information Governance Group.

\section{Acknowledgements}

The authors thank NHS South, Central and West Commissioning Support Unit and the Care and Health Information Exchange Information Governance Group for their support, and for provision of access to CHIA data.

They would also like to thank Mary O'Brien, NHS England and Jean Hughes, Patient and Public Involvement contributor for their support of this research. 


\section{References}

1. The state of musculoskeletal health 2019. Versus Arthritis 2019. https://www.versusarthritis.org/media/14594/state-of-musculoskeletal-health-2019.pdf. Accessed 14/01/2022

2. Pasvol TJ, Horsfall L, Bloom S, Segal AW, Sabin C, Field N, Rait G. Incidence and prevalence of inflammatory bowel disease in UK primary care: a population-based cohort study. BMJ Open. 2020;10(7):e036584. doi: 10.1136/bmjopen-2019-036584.

3. National Institute for Health and Care Excellence (2018). Rheumatoid arthritis in adults: management. NG100 (NICE, London). https://www.nice.org.uk/guidance/ng100 Accessed $10 / 01 / 2022$

4. National Institute for Health and Care Excellence (2019). Ulcerative colitis: management. NG130 (NICE, London). https://www.nice.org.uk/guidance/ng130 Accessed 10/01/2022

5. National Institute for Health and Care Excellence (2019). Crohn's disease: management. NG129, (NICE, London). https://www.nice.org.uk/guidance/ng129 Accessed 10/01/2022

6. Smolen JS, Landewé R, Bijlsma J et al. EULAR recommendations for the management of rheumatoid arthritis with synthetic and biological disease-modifying antirheumatic drugs: 2016 update. Ann Rheum Dis. 2017;76(6):960-977

7. National Institute for Health and Care Excellence (2018). NICE Clinical Knowledge Summaries DMARDs. https://cks.nice.org.uk/dmards Accessed 13/12/2021

8. Lythgoe MP, Abraham S. Good practice in shared care for inflammatory arthritis. $\mathrm{Br} \mathrm{J}$ Gen Pract. 2016;66(646):275-7. doi: 10.3399/bjgp16X685177.

9. Rheumatoid arthritis in adults: diagnosis and management. Evidence review F DMARDs. NICE guideline NG100 Intervention evidence review. NICE July 2018. https://www.nice.org.uk/guidance/ng100/evidence. Accessed 14/01/2022

10. Yahia S, El-Hadidy MA, El-Gilany AH, Anwar R, Darwish A, Mansour AK. Predictors of anxiety and depression in Egyptian thalassemic patients: a single center study. Int J Hematol. 2013;97(5):604-9.

11. Gaffari Saravi V, Zarghami M, Tirgari A, Ebrahimi E. Relationship between thalassemia and depression. Res J Biol Sci. 2007;2(3):280-4.

12. Gregory ME, Russo E, Singh H. Electronic Health Record Alert-Related Workload as a Predictor of Burnout in Primary Care Providers. Appl Clin Inform. 2017;8(3):686-697.

13. Shanafelt TD, Dyrbye LN, Sinsky C, Hasan O, Satele D, Sloan J, West CP. Relationship Between Clerical Burden and Characteristics of the Electronic Environment With Physician Burnout and Professional Satisfaction. Mayo Clin Proc. 2016;91(7):836-48.

14. Rigby WFC, Lampl K, Low JM, Furst DE. Review of Routine Laboratory Monitoring for Patients with Rheumatoid Arthritis Receiving Biologic or Nonbiologic DMARDs. Int J Rheumatol. 2017; 9614241. doi: 10.1155/2017/9614241

15. Johnson M, Hounkpatin H, Fraser SD, Culliford D, Uniacke M, Roderick PJ. Using a linked database for epidemiology across the primary and secondary care divide: acute kidney injury. BMC Medical Informatics and Decision Making 2017:106. doi: 10.1186/s12911-017-0503-8

16. NHS Digital. Read codes. https://digital.nhs.uk/services/terminology-and-classifications/readcodes. Accessed 13/12/2021

17. Department for Communities and Local Government. English Indices of Deprivation. 2015. https://www.gov.uk/government/statistics/english-indices-of-deprivation-2015 (Accessed 13/12/2021)

18. Hounkpatin HO, Fraser SDS, Johnson MJ, Harris S, Uniacke M, Roderick PJ. The association of socioeconomic status with incidence and outcomes of acute kidney injury. Clin Kidney $J$ 2019;13(2):245-252. doi: https://doi.org/10.1093/ckj/sfz113

19. $R$ Core Team, 2020. R: A language and environment for statistical computing. $R$ Foundation for 
Statistical Computing, Vienna, Austria.

20. Benchimol El, Smeeth L, Guttmann A, Harron K, Moher D, Petersen I, Sørensen HT, von Elm E, Langan SM; RECORD Working Committee. The REporting of studies Conducted using Observational Routinely-collected health Data (RECORD) Statement. PLoS Med. 2015;12(10):e1001885.

21. Edwards CJ, Campbell J, van Staa T, Arden NK. Regional and temporal variation in the treatment of rheumatoid arthritis across the UK: a descriptive register-based cohort study. BMJ Open. 2012;2(6):e001603. doi: 10.1136/bmjopen-2012-001603

22. Jones GR, Lyons M, Plevris N, Jenkinson PW, Bisset C, Burgess C, Din S, Fulforth J, Henderson P, Ho GT, Kirkwood K, Noble C, Shand AG, Wilson DC, Arnott ID, Lees CW. IBD prevalence in Lothian, Scotland, derived by capture-recapture methodology. Gut. 2019;68(11):1953-1960. doi: 10.1136/gutjnl-2019-318936.

23. Stournaras E, Qian W, Pappas A, Hong YY, Shawky R; UK IBD BioResource Investigators, Raine T, Parkes M; UK IBD Bioresource Investigators. Thiopurine monotherapy is effective in ulcerative colitis but significantly less so in Crohn's disease: long-term outcomes for 11928 patients in the UK inflammatory bowel disease bioresource. Gut. 2021;70(4):677-686. doi: 10.1136/gutjnl-2019-320185.

24. Mori S, Hidaka M, Kawakita T, Hidaka T, Tsuda H, Yoshitama T, Migita K, Ueki Y. Factors Associated with Myelosuppression Related to Low-Dose Methotrexate Therapy for Inflammatory Rheumatic Diseases. PLoS One 2016. 29;11(4):e0154744

25. Gisbert JP, Gomollón F. Thiopurine-induced myelotoxicity in patients with inflammatory bowel disease: a review. Am J Gastroenterol. 2008;103(7):1783-800.

26. Visser K, van der Heijde DM. Risk and management of liver toxicity during methotrexate treatment in rheumatoid and psoriatic arthritis: a systematic review of the literature. Clin Exp Rheumatol. 2009;27(6):1017-25.

27. Gelfand JM, Wan J, Zhang H, Shin DB, Ogdie A, Syed MN, Egeberg A. Risk of liver disease in patients with psoriasis, psoriatic arthritis, and rheumatoid arthritis receiving methotrexate: a population-based study. J Am Acad Dermatol. 2021:S0190-9622(21)00343-1. doi: 10.1016/j.jaad.2021.02.019.

28. Pavy S, Constantin A, Pham T, Gossec L, Maillefert JF, Cantagrel A, Combe B, Flipo RM, Goupille P, Le Loët X, Mariette X, Puéchal X, Schaeverbeke T, Sibilia J, Tebib J, Wendling D, Dougados M. Methotrexate therapy for rheumatoid arthritis: clinical practice guidelines based on published evidence and expert opinion. Joint Bone Spine. 2006;73(4):388-95.

29. Conway R, Carey JJ. Risk of liver disease in methotrexate treated patients. World J Hepatol. 2017;9(26):1092-1100.

30. Spencer NJ, Fryer AA, Farmer AD, Duff CJ. Blood test monitoring of immunomodulatory therapy in inflammatory disease. BMJ. 2021;8;372:n159. doi: 10.1136/bmj.n159.

31. Improving outcomes through personalised medicine. NHS England, 2016. https://www.england.nhs.uk/wp-content/uploads/2016/09/improving-outcomes-personalisedmedicine.pdf. Accessed 14/01/2022

32. Stratified medicine in the NHS. Association of the British Pharmaceutical Industry, 2014

33. Dejaco C, Alunno A, Bijlsma JW, Boonen A, Combe B, Finckh A, Machado PM, Padjen I, Sivera $F$, Stamm TA, Buttgereit F. Influence of COVID-19 pandemic on decisions for the management of people with inflammatory rheumatic and musculoskeletal diseases: a survey among EULAR countries. Ann Rheum Dis 2020;80:518-26.doi:10.1136/annrheumdis-2020-218697.

34. British Society for Rheumatology Covid-19 Guidance. https://www.rheumatology.org.uk/practice-quality/covid-19-guidance. Accessed 10/12/2021 
Tables

Table 1: Cohort characteristics at baseline

\begin{tabular}{|c|c|c|c|}
\hline \multicolumn{2}{|l|}{ Characteristic } & \multirow{2}{*}{$\begin{array}{r}\text { Number } \\
\\
52\end{array}$} & \multirow{2}{*}{$\begin{array}{r}\text { Percentage } \\
\text { (unless } \\
\text { stated } \\
\text { otherwise) } \\
18-110\end{array}$} \\
\hline \multirow[t]{2}{*}{ Age } & Median (range) & & \\
\hline & Mean (SD) & 51.9 & 18.8 \\
\hline \multirow[t]{4}{*}{ Age groups } & 18 to 39 & 210047 & 30 \\
\hline & 40 to 59 & 241831 & 34 \\
\hline & 60 to 79 & 194168 & 28 \\
\hline & 80 and above & 56219 & 8 \\
\hline \multirow[t]{2}{*}{ Sex } & Female & 373,553 & 53.2 \\
\hline & Male & 328,712 & 46.8 \\
\hline \multirow{6}{*}{$\begin{array}{l}\text { Socioeconomic } \\
\text { status (IMD } \\
\text { quintile) }\end{array}$} & 1 (most deprived) & 102,796 & 14.6 \\
\hline & 2 & 126,069 & 18.0 \\
\hline & 3 & 132,262 & 18.8 \\
\hline & 4 & 146,622 & 20.9 \\
\hline & 5 (least deprived) & 186,284 & 26.5 \\
\hline & Missing & 8232 & 1.2 \\
\hline \multirow[t]{6}{*}{ Ethnicity } & British \& Mixed British/Irish/Other White & 427,019 & 61.8 \\
\hline & $\begin{array}{l}\text { Mixed (White \& Asian/ White and Black } \\
\text { African/White and Black Caribbean/Other Mixed) }\end{array}$ & 3863 & 0.6 \\
\hline & Indian/Bangladeshi/Pakistani/other Asian & 13,180 & 1.9 \\
\hline & African/Caribbean/Other Black & 5251 & 0.7 \\
\hline & Other & 7236 & 1.0 \\
\hline & Missing & 245,716 & 35.0 \\
\hline \multirow{8}{*}{$\begin{array}{l}\text { Long term } \\
\text { conditions } \\
\text { diagnosed at } \\
\text { baseline }\end{array}$} & Rheumatoid arthritis & 6723 & 0.9 \\
\hline & Inflammatory bowel disease & 7834 & 1.1 \\
\hline & Hypertension & 150,458 & 21.4 \\
\hline & Osteoarthritis & 95,294 & 13.6 \\
\hline & Diabetes & 62,767 & 8.9 \\
\hline & Cardiovascular disease (CVD) & 52,985 & 7.5 \\
\hline & Chronic kidney disease (CKD) & 36,731 & 5.2 \\
\hline & Heart failure (including cor pulmonale) & 12,799 & 1.8 \\
\hline \multirow{6}{*}{$\begin{array}{l}\text { Prescribed at } \\
\text { baseline }\end{array}$} & Methotrexate & 2214 & 0.3 \\
\hline & Azathioprine & 746 & 0.1 \\
\hline & Non-steroidal anti-inflammatory drug & 19,364 & 2.8 \\
\hline & Diuretics & 35,912 & 5.1 \\
\hline & Angiotensin-converting enzyme Inhibitors & 55,606 & 7.9 \\
\hline & Renin Angiotensin 2 blockers & 25,345 & 3.6 \\
\hline
\end{tabular}

Abbreviations: SD - standard deviation, IMD - Index of Multiple Deprivation,

Note: Cardiovascular disease (CVD) included ischaemic heart disease, cerebrovascular disease and peripheral vascular disease. 
Table 2: Characteristics of people with rheumatoid arthritis and inflammatory bowel disease not experiencing blood test abnormalities over two years

\begin{tabular}{|c|c|c|c|c|c|}
\hline & & $\begin{array}{l}\text { People with RA on } \\
\text { methotrexate } \\
\text { (prevalent and } \\
\text { incident) not } \\
\text { experiencing any } \\
\text { of the NICE- } \\
\text { specified blood } \\
\text { test abnormalities } \\
\\
\text { Number (row \%) } \\
\text { unless otherwise } \\
\text { stated }\end{array}$ & $\begin{array}{c}\text { All people with RA } \\
\text { on } \\
\text { methotrexate } \\
\text { (prevalent and } \\
\text { incident) }\end{array}$ & $\begin{array}{c}\text { People with IBD } \\
\text { on azathioprine } \\
\text { (prevalent and } \\
\text { incident) not } \\
\text { experiencing any } \\
\text { of the NICE- } \\
\text { specified blood } \\
\text { test abnormalities } \\
\text { Number (row \%) } \\
\text { unless otherwise } \\
\text { stated }\end{array}$ & $\begin{array}{l}\text { All people with } \\
\text { IBD on } \\
\text { azathioprine } \\
\text { (prevalent and } \\
\text { incident) } \\
\\
\text { Number }\end{array}$ \\
\hline \multicolumn{2}{|l|}{ Total } & $1585(52.8)$ & 3001 & $657(56.5)$ & 1162 \\
\hline \multirow[t]{2}{*}{ Age } & Median (range) & 63 (53 to 71) & $66(56$ to 75$)$ & 43 (32 to 54$)$ & 44 (32 to 58$)$ \\
\hline & Mean (SD) & $61(14)$ & $65(14)$ & $44(15)$ & $46(17)$ \\
\hline \multirow[t]{4}{*}{ Age groups } & 18 to 39 & $113(71.1)$ & 159 & $279(57.8)$ & 482 \\
\hline & 40 to 59 & $547(63.8)$ & 857 & $275(65.0)$ & 423 \\
\hline & 60 to 79 & $805(50.1)$ & 1583 & $100(43.5)$ & 230 \\
\hline & 80 and above & $119(29.6)$ & 402 & Suppressed & 27 \\
\hline \multirow[t]{2}{*}{ Sex } & Male & $495(50.9)$ & 972 & $330(58.1)$ & 568 \\
\hline & Female & $1089(53.7)$ & 2029 & $329(55.4)$ & 594 \\
\hline \multirow{6}{*}{$\begin{array}{l}\text { Socioecono } \\
\text { mic status } \\
\text { (IMD } \\
\text { quintile) }\end{array}$} & $\begin{array}{l}1 \text { (most } \\
\text { deprived) }\end{array}$ & $208(52.7)$ & 395 & $85(52.5)$ & 162 \\
\hline & 2 & $248(52.9)$ & 469 & $102(53.7)$ & 190 \\
\hline & 3 & $294(52.4)$ & 561 & $131(54.1)$ & 242 \\
\hline & 4 & $355(53.2)$ & 667 & $173(64.1)$ & 270 \\
\hline & $\begin{array}{l}5 \text { (least } \\
\text { deprived) }\end{array}$ & $466(52.4)$ & 889 & $157(56.1)$ & 280 \\
\hline & Missing & $13(65.0)$ & 20 & $11(61.1)$ & 18 \\
\hline \multirow{6}{*}{$\begin{array}{l}\text { Long term } \\
\text { conditions } \\
\text { at baseline }\end{array}$} & CKD & $60(14.9)$ & 403 & $10(21.3)$ & 47 \\
\hline & CVD & $148(29.9)$ & 495 & $16(23.9)$ & 67 \\
\hline & Heart failure & $26(15.5)$ & 168 & Suppressed & 22 \\
\hline & Diabetes & $142(34.0)$ & 418 & $33(33.3)$ & 99 \\
\hline & Hypertension & $524(41.2)$ & 1271 & $70(37.8)$ & 185 \\
\hline & Osteoarthritis & 429 (39.9) & 1076 & $42(40.4)$ & 104 \\
\hline
\end{tabular}

NICE-recommended test thresholds: 1$)$ WBC (3.5 $\times 10^{9} / \mathrm{L}$ or above), 2) Mean cell volume (MCV) (105fL or less), 3) Neutrophils $1.6 \times 10^{9} / \mathrm{L}$ or above), 4) Platelets ( $140 \times 10^{9} / \mathrm{L}$ or above), 5) (Eosinophils $\left(0.5 \times 10^{9} / \mathrm{L}\right.$ or less, 6$)$ ALT (100 U/L or less), 7) AST (100 U/L or less), 8) Albumin (30g/L or more), 9) eGFR (60ml/min or more) Suppressed $=$ data not provided for confidentiality reasons due to small numbers in this category. 
Table 3. Multivariable associations between patient characteristics and not experiencing any blood test abnormalities among those with RA prescribed methotrexate and those with IBD prescribed azathioprine using NICE-specified thresholds and tests.

\begin{tabular}{|c|c|c|c|c|c|}
\hline \multirow{2}{*}{\multicolumn{2}{|c|}{$\begin{array}{l}\text { Rheumatoid arthritis (RA) - methotrexate * } \\
\text { Characteristic }\end{array}$}} & \multirow{2}{*}{$\begin{array}{l}\text { Odds } \\
\text { ratio }\end{array}$} & \multicolumn{2}{|r|}{$N$} & \\
\hline & & & $\begin{array}{l}95 \% \text { confid } \\
\text { interva }\end{array}$ & ence & $\mathbf{p}$ \\
\hline \multirow{3}{*}{$\begin{array}{l}\text { Age groups } \\
\text { (vs. } 18 \text { to } 39 \text { ) }\end{array}$} & 40 to 59 & 0.79 & 0.55 & 1.13 & 0.21 \\
\hline & 60 to 79 & 0.56 & 0.39 & 0.79 & $<0.001$ \\
\hline & 80 and above & 0.26 & 0.17 & 0.40 & $<0.001$ \\
\hline Sex (vs. male) & Female & 1.11 & 0.94 & 1.30 & 0.22 \\
\hline \multirow{4}{*}{$\begin{array}{l}\text { Socioeconomic } \\
\text { status IMD } \\
\text { quintile (vs. 5, } \\
\text { least deprived) }\end{array}$} & 4 & 0.95 & 0.77 & 1.17 & 0.61 \\
\hline & 3 & 0.96 & 0.77 & 1.20 & 0.70 \\
\hline & 2 & 0.95 & 0.75 & 1.21 & 0.69 \\
\hline & 1 (most deprived) & 0.90 & 0.70 & 1.16 & 0.40 \\
\hline \multirow{4}{*}{$\begin{array}{l}\text { Long term } \\
\text { conditions }\end{array}$} & CKD (vs. no CKD) & 0.37 & 0.21 & 0.67 & $<0.001$ \\
\hline & CVD (vs. no CVD) & 0.51 & 0.30 & 0.85 & 0.01 \\
\hline & Diabetes (Type 1 or 2 vs. no diabetes) & 0.66 & 0.51 & 0.83 & $<0.001$ \\
\hline & Hypertension (vs. no hypertension) & 0.93 & 0.79 & 1.10 & 0.41 \\
\hline \multicolumn{6}{|c|}{ Inflammatory bowel disease (IBD) - azathioprine * } \\
\hline \multirow{3}{*}{$\begin{array}{l}\text { Age groups } \\
\text { (vs. } 18 \text { to } 39 \text { ) }\end{array}$} & 40 to 59 & 1.35 & 1.03 & 1.79 & 0.03 \\
\hline & 60 to 79 & 0.65 & 0.45 & 0.93 & 0.02 \\
\hline & 80 and above & 0.09 & 0.01 & 0.33 & 0.002 \\
\hline Sex (vs. male) & Female & 0.96 & 0.75 & 1.22 & 0.72 \\
\hline \multirow{4}{*}{$\begin{array}{l}\text { Socioeconomic } \\
\text { status IMD } \\
\text { quintile (vs. } 5 \text {, } \\
\text { least deprived) }\end{array}$} & 4 & 1.41 & 0.99 & 2.01 & 0.06 \\
\hline & 3 & 0.90 & 0.63 & 1.28 & 0.55 \\
\hline & 2 & 0.83 & 0.57 & 1.22 & 0.34 \\
\hline & 1 (most deprived) & 0.85 & 0.57 & 1.26 & 0.41 \\
\hline \multirow{3}{*}{$\begin{array}{l}\text { Long term } \\
\text { conditions }\end{array}$} & CKD (vs. no CKD) & 0.39 & 0.17 & 0.82 & 0.02 \\
\hline & Diabetes (Type 1 or 2 vs. no diabetes) & 0.57 & 0.35 & 0.94 & 0.03 \\
\hline & Hypertension (vs. no hypertension) & 0.91 & 0.61 & 1.36 & 0.64 \\
\hline
\end{tabular}

Models adjusted for age, sex, socioeconomic status and long-term conditions. Small numbers with CVD and heart failure in the IBD/azathioprine group meant that this condition combination was not included in the multivariable model as it was for the RA/methotrexate group.

Abbreviations: IMD - Index of Multiple Deprivation, CVD - cardiovascular disease (including ischaemic heart disease, cerebrovascular disease, heart failure and peripheral vascular disease), NSAID - non-steroidal antiinflammatory drug, RAASi - renin-angiotensin-aldosterone system inhibitor. CKD - chronic kidney disease (excluding dialysis and transplant). IBD - inflammatory Bowel Disease. RA - Rheumatoid Arthritis

*'RA - methotrexate' = prevalent and incident RA patients prescribed methotrexate in any 2 month period over the study period. 'IBD-azathioprine' = prevalent and incident IBD patients prescribed azathioprine in any 2 month period over the study period.

NICE thresholds: 1) WBC(3.5 x 10\%/L or above), 2) Mean cell volume (MCV) (105fL or less), 3) Neutrophils $1.6 \mathrm{x}$ $10 \% / \mathrm{L}$ or above), 4) Platelets (140 $\times 10 \% / \mathrm{L}$ or above), 5) (Eosinophils $\left(0.5 \times 10^{9} / \mathrm{L}\right.$ or less, 6$) \mathrm{ALT}$ (100 U/L or less), 7) AST (100 U/L or less), 8) Albumin (30g/L or more), 9) eGFR (60ml/min or more). 
Figure headings and legends

Figure 1. - Flow diagram of study participants

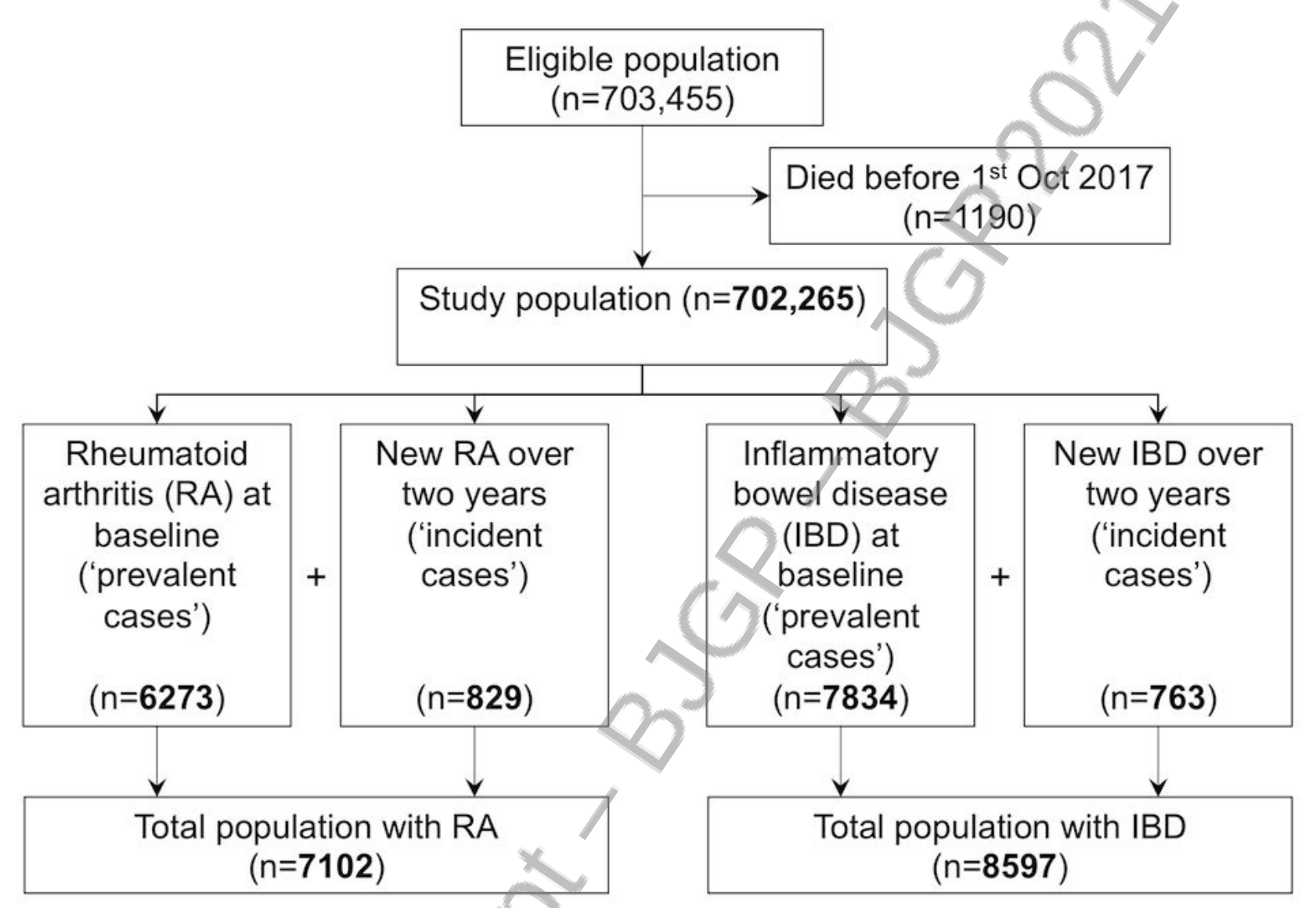


Figure 2. Proportion of people with RA taking methotrexate continuously (3a) and IBD taking azathioprine continuously (3b) who had blood tests by number of three-month testing periods.

$2 a$

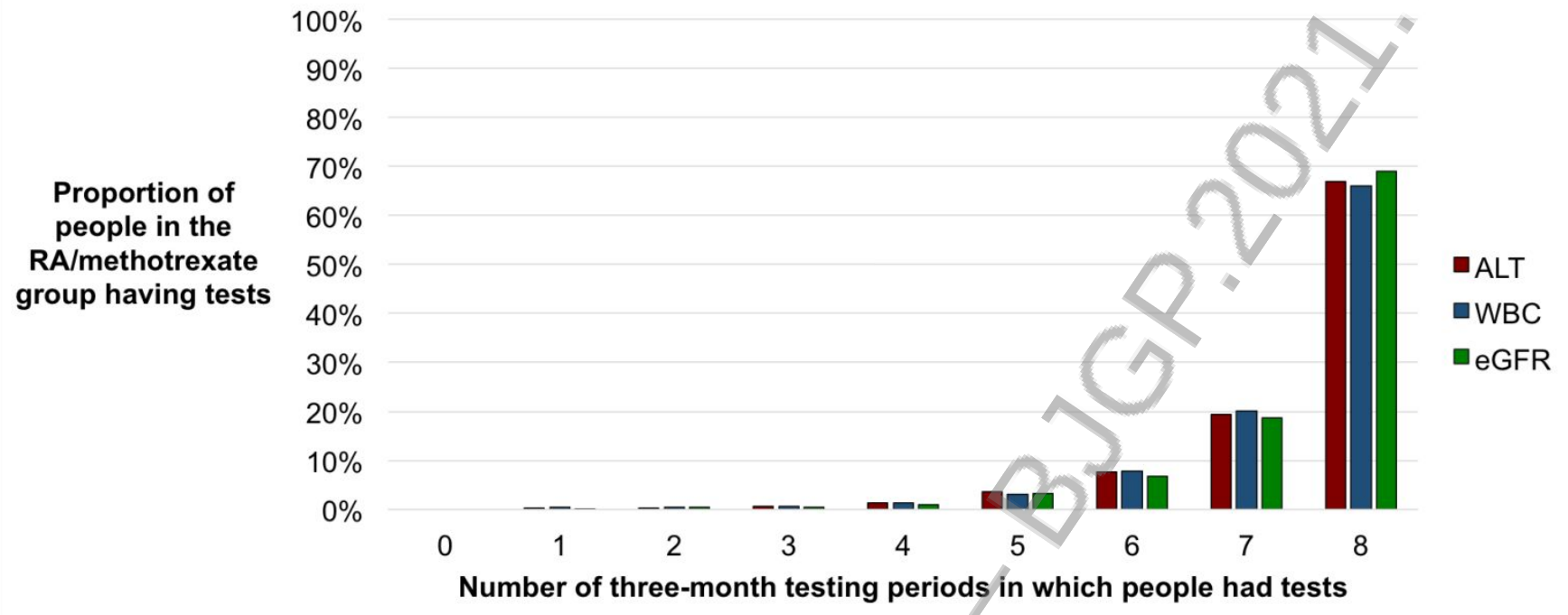

2b

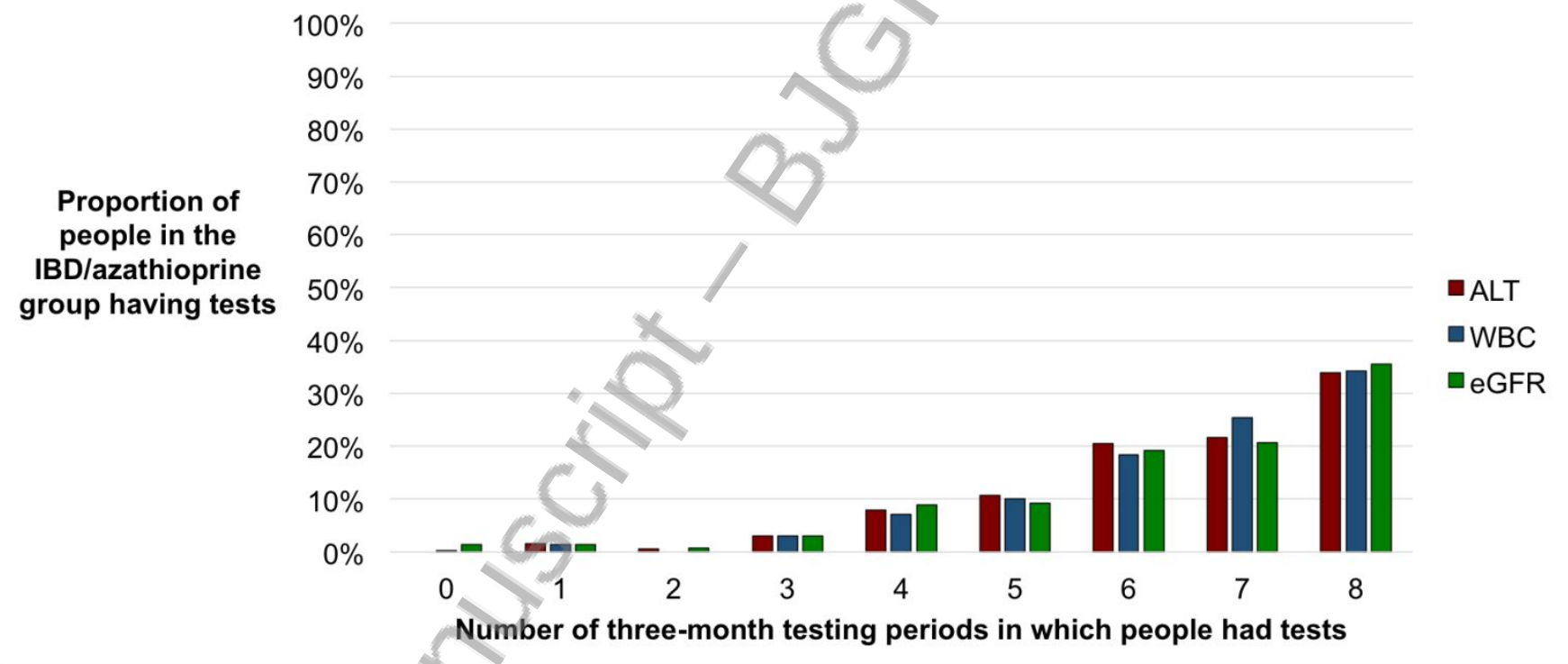

Footnote for Figure 2:

Abbreviations:

$\mathrm{WBC}=$ white blood count, $\mathrm{ALT}=$ alanine aminotransferase, eGFR = estimated glomerular filtration rate, $\mathrm{RA}=$ rheumatoid arthritis, IBD = inflammatory bowel disease .

Total study period $=24$ months. 
Figure 3. Normal blood test proportions for specific tests by exposure categories among people with RA taking methotrexate (3a) and people with IBD taking azathioprine (3b)

$3 a$

\section{Proportion with normal tests}

0\% $10 \%$ 20\% $30 \%$ 40\% $50 \%$ 60\% $70 \%$ 80\% $90 \% 100 \%$

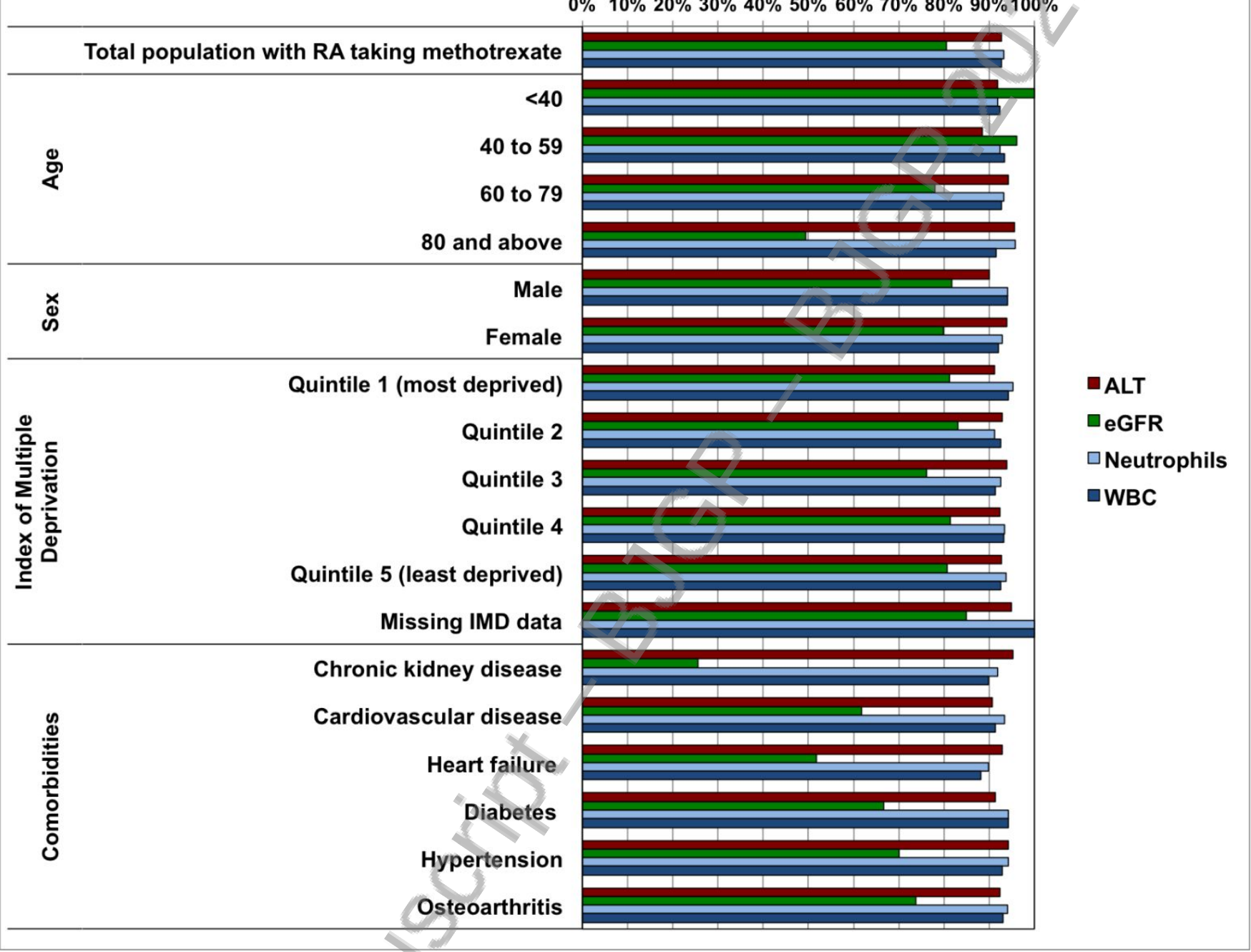




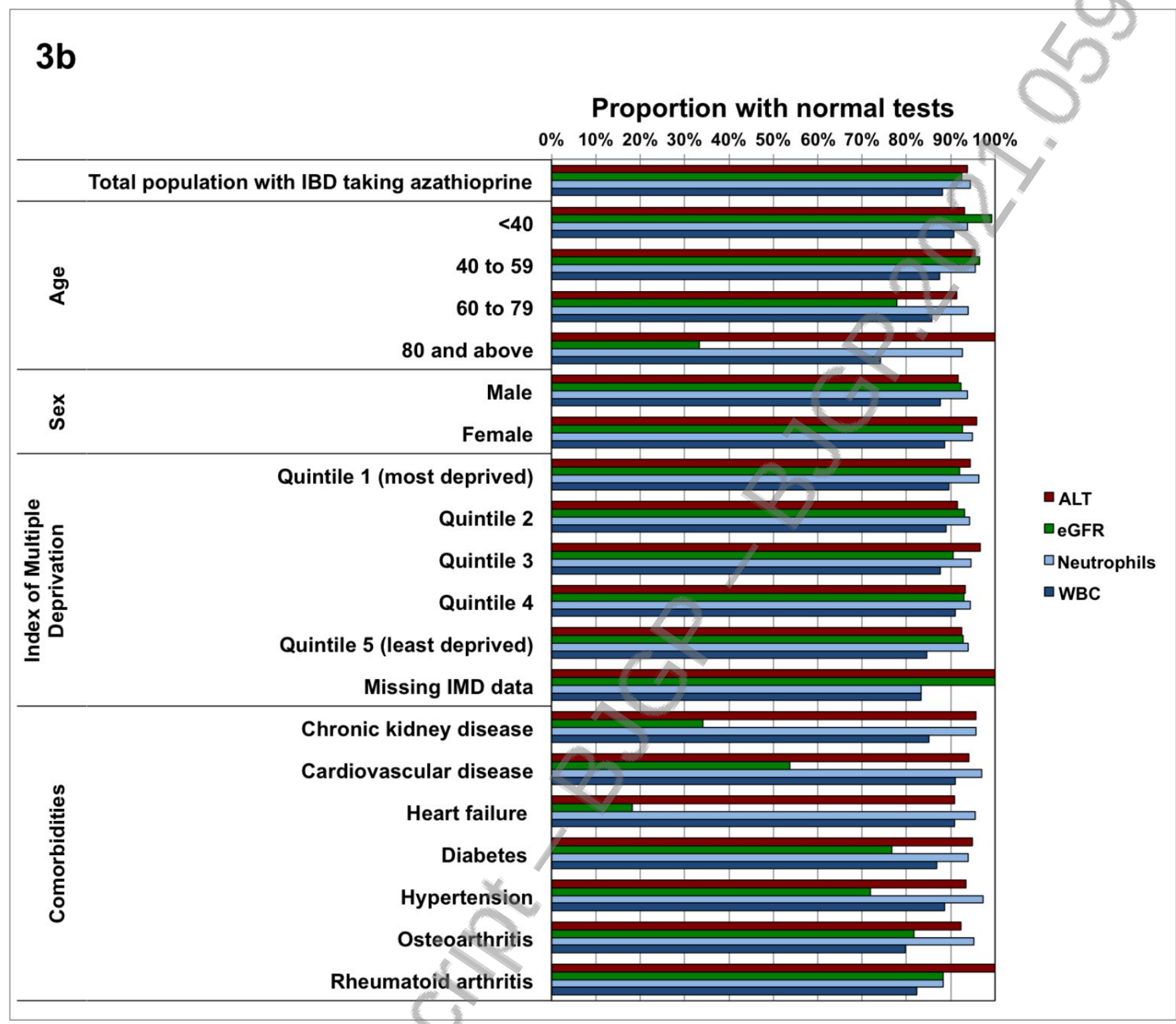

\section{Footnote to figure 3:}

NICE-recommended test thresholds: 1) WBC (3.5 x 10\%/L or above), 2) ALT (100 U/L or less) 3) Neutrophils $\left(1.6 \times 10^{9} / \mathrm{L}\right.$ or above $\left.) 4\right)$ eGFR $\left(60 \mathrm{ml} / \mathrm{min} / 1.73 \mathrm{~m}^{2}\right.$ or more) 